\title{
DIVERSIFYING THE ENGINEERING VOICES: BRINGING DIVERSE PROFESSIONALS TO THE CLASSROOM THROUGH VIDEO INTERVIEWS
}

\author{
Grace Couper and Jennifer Long \\ McMaster University, School of Engineering Practice \& Technology \\ couperrg@mcmaster.ca, longjen@mcmaster.ca
}

\begin{abstract}
This paper will discuss the importance of using videos in the classroom and the significance of adding diversity to teaching and learning, particularly in engineering and technology. Increasing diversity is a common goal seen in many institutions, including the Faculty of Engineering at McMaster University. Beginning in Fall 2017, instructors from the Bachelor of Technology program, in the School of Engineering Practice and Technology (SEPT) will integrate recorded video interviews of diverse professionals into the classroom, hopefully putting the goal more within reach. These videos will depict professionals in engineering fields who identify as young, female or visible minorities. In these interviews, the participants will discuss a variety of topics including: the importance of communication skills in a professional environment; the advantages of participating in co-op programs; life after graduation; as well as other topical issues. In addition to the proven benefits of learning through videos, students will hear from various professionals of different backgrounds thereby adding diversity to the engineering classroom.
\end{abstract}

Keywords: videos, technology in the classroom, engineering technology, gender, ethnicities

\section{INTRODUCTION}

As of Fall 2017, management instructors from the Bachelor of Technology (B. Tech.) program will show first-year students recorded interviews with engineering professionals with diverse backgrounds. B.Tech. is a skillsbased engineering technology and management program at the university level. The program is a partnership between McMaster University Faculty of Engineering and Mohawk College's School of Engineering Technology. The program combines traditional lectures with hands-on experience in high-tech modern labs, as well as real-life industry experience (a 12-month workplace co-op is mandatory for students to graduate) in three areas of specialization: Automotive and Vehicle Technology (AVT), Biotechnology (BIO), and Process Automation Technology (PAT). The B.Tech. program also uniquely blends engineering technology with management and societal courses to explore the human side of engineering. The aim is to produce T-shaped graduates equally well- informed in technical as well as management skills, and who have breadth of perspective to tackle broad-based engineering issues in creative and practical ways. [17]. Despite its focus on graduating well-rounded students, this program does not overtly teach students how to deal with Canada's growing workplace diversity. As one of Canada's Best Diversity Employers since 2014, the Royal Bank of Canada defines diversity as "any dimension that can be used to differentiate groups and people from one another. It means respect for and appreciation of differences in ethnicity, gender, age, national origin, disability, sexual orientation, education, and religion" [20] With estimates of diversity in the workplace growing to over $50 \%$, it is imperative that postsecondary institutions prepare students to thrive in a diverse environment; one place to start is in the front of engineering classrooms.

In 2006, women represented just $33.1 \%$ of all Canadian university teachers; further, visible minority faculty members (both male and female) represented only $17 \%$ of the entire faculty. In subjects like Engineering and Applied Sciences, women represent only $12 \%$ of faculty [3]. To understand the gendered, ethnic, racial, or age makeup of any faculty is an imperfect science as polls and surveys regarding personal and identity-related information are required by law to be voluntary. To give a sense of the diversity within our program (note: using a list of names of instructors teaching in the academic year 2015-2016 and therefore, are estimates at best), the Bachelor of Technology employed approximately 80 male instructors and 20 female instructors. These estimates include both full-time and sessional faculty members, however (and as is typical in most post-secondary institutions in North America), the majority of instructors are sessional faculty members and as such, these percentages would change over time. There are currently only 3 full-time female faculty and approximately 20 full-time male faculty members. While these gender estimates would not describe the ethnic diversity found within our program, which we can anecdotally describe as significant, our program has fewer female instructors as is similar to other Canadian engineering programs.

The Bachelor of Technology program has a similar gendered makeup among the student population. According to program-wide poll in the same year, male students represented $97 \%$ of the cohort in AVT, $65 \%$ in $\mathrm{BIO}$ and $88 \%$ in PAT. Or on average, $83 \%$ male student 
body. As with the instructors' ethnic diversity, the students' ethnic diversity is unknown but anecdotally understood to be relatively diverse. McMaster's Faculty of Engineering, of which the Bachelor of Technology is housed, their goal is to increase the number of female students in their programs.

Dee [9] argues that students see their teacher or lecturer as a role-model most often when the lecturer is the same racial or gendered identity as the student. Further, as argued by Hoffmann \& Oreopoulos, students are more intellectually engaged when taught by instructors with similar identities [12]. As described above, the gendered, age, and (from what we can estimate) ethnic identities of the students and faculty could be further aligned.

Due to institutional constraints around hiring, diversifying instructors will be a long process but not one without merit. In the meantime, the Bachelor of Technology program seeks to create and integrate multimedia showcasing professional workplace experiences from individuals of minority racial, gendered, and age identities (in the field of Canadian engineering education and workplace) as a means to diversify the voices heard in the classroom. These diverse experiences and expertise would also work to engage a broader range of students and open up the idea of the diverse Canadian workplace for all students. Students usually appreciate material found by their lecturers, as they view it as 'validated' and appreciate the opportunity to spend class time going over and discussing the material [23].

In this paper, we will identify the pedagogical benefits to using multimedia in the classroom, including multiple learning styles provided allowing more students to be engaged and easing the work of the memory. Other areas of focus include video use to diversify student perceptions of engineering professionals and the Canadian workplace, as well as our intended process including questions we will ask professionals. We will also discuss our future associated research. This paper provides a preliminary overview of this project and its intended impact in the classroom.

\section{BENEFITS OF USING VIDEO TECHNOLOGY}

Videos and other forms of technology have been used to assist teachers in many subjects and for a variety of reasons. Instructional videos are one of the best methods for teaching students of all ages how to think and learn and, they can increase self-expression, cooperative learning, individualization, and student engagement [13]. Students enjoy getting the opinion of someone else other than their instructors [23] and tend to trust the content of the videos presented. By using professionals and other community members, student perceptions of what constitutes local and global communities can be broadened and student learning can be enhanced [6]. Below, we briefly describe the three reasons why we chose to create videos instead of hosting professional panels or a speakers' series with similarly identified individuals.

\subsection{Deeper Learning}

A very important aspect of learning is being able to recall what was taught. There are three sections to the memory which allow for information to be inputted, processed and integrated, and stored. The sensory memory is the first section information reaches, which holds an exact copy of the occurrence for less than a quarter of a second. Information then goes through a process where only important aspects can pass to the working memory however, the working memory is only able to hold the processed information for less than thirty seconds. The working memory organizes the important information into verbal and visual models. Before the data can enter the long-term memory, past knowledge is drawn upon to be integrated with the new verbal and visual models. The integrated models can then enter the long-term memory where other knowledge is kept, and can be stored for long periods of time [18]. Meaningful learning occurs when relevant words and images are selected for processing in the working memory, organized into an appropriate model, and finally the representations are integrated with each other and with previous knowledge [22]. Videos should therefore assist students in remembering what is being taught, as it includes words and images, and will include some information students have previously learnt.

\subsection{Reducing Cognitive Load}

Cognitive Load Theory (CLT) proposes multimedia materials should reduce the cognitive load, while enhance the working memory while learning [4]. Cognitive load can include the teaching style used, or distractions, and require some memory to be comprehended, reducing the amount of memory available to the content being taught. By reducing the amount of memory used to process the method of teaching, which could be done by altering the method of teaching to be easier for students to grasp and reducing distractions, learners would be able to use more memory resources to take in and comprehend more information.

Cognitive Theory of Multimedia Learning (CTML) was proposed by Richard E. Mayer and reasons that multimedia supports the way the human brain learns [22]. CTML is similar to CLT and is based on 3 assumptions, including the dual-channel assumption, limited capacity assumption, and active processing assumption. The dual-channel assumption believes that the working memory has both auditory and visual channels, the limited capacity assumption infers that each subsystem of the working memory has limited capacity, and the active processing 
assumption figures people construct knowledge in a meaningful way if they are able to pay attention to the relevant material, organize, and integrate it with their prior knowledge [22]. CTML shows narration and images producing verbal and visual models that get integrated with prior knowledge [5], and can be seen in Figure 1. The video project will follow both CMT and CTML to assist the ease of learning.

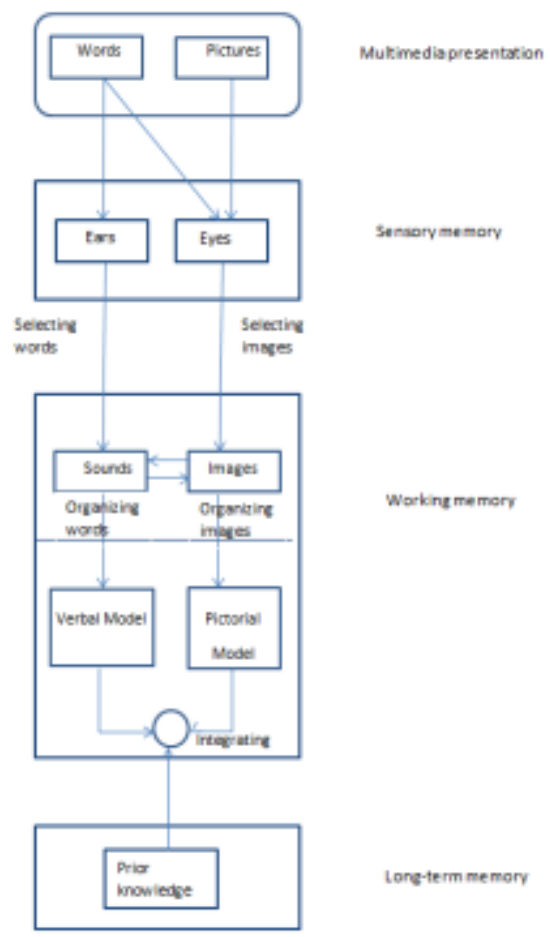

Figure 1: The Cognitive Theory of Multimedia Learning (CTML) [18]

\subsection{Learning Styles}

Multimedia can help people learn more easily because it is able to benefit many learning styles. Students have a variety of learning styles they prefer and find easiest to comprehend, so their environment should offer multiple resources, which might require adding technology [7]. The VARK (Visual, Aural, Reading and Kinesthetic) instrument proposed by Fleming gives four modalities that students prefer to learn through; visual, aural, reading/writing, and kinesthetic (multi-sensory). Students learn easiest with their preferred learning style, which could be a combination of any number of modalities. In fact, almost one third of students prefer having a combination of the four modes, and almost two thirds prefer a combination of styles, as opposed to only using one modality. Kinesthetic is the most preferred modality by both males and females, and visual is the least preferred modality [1]. As most students prefer a combination of modalities, using a variety of learning styles would be the most beneficial to the majority of students. By using videos and other multimedia, the visual, aural, kinesthetic and perhaps reading modalities are used, accommodating most students to easier learning [8]. A study performed by Chen showed video-based multimedia benefits both verbalizers and visualizers, as verbalizers had high sustained attention and visualizers generated the highest cognitive load when voice-over was used [5].

The video interview project will ideally allow more students to be able to better pay attention by utilizing multiple learning styles and allow for more information to be processed and remembered, as seen in CLT and CTML.

\section{VIDEO PROJECT}

These videos will be developed by the Communications and Management instructors and their Special Projects Undergraduate Assistant in the spring of 2017. The instructors will identify potential candidates through their network and invite them to participate. The instructors also have access to engineering professionals through the faculty's co-op and career services office.

Due to funding constraints, a pilot project of three videos (3 female engineers working in southwestern Ontario) will be completed and introduced into classes before producing more videos. McMaster's teaching and learning institute will aid in the planning, recording, and editing process. The outcome of this production will be a series of five, short, $3-5$ minute videos from each participant. The instructors have submitted an ethics proposal to McMaster's Research Ethics Board as this project constitutes a systematic collection of data. Student perceptions of these videos will be gathered using focus groups in the Spring of 2018 in order to understand their impact for students and their potential role in diversifying students' perceptions of engineers and voices in the classroom. With this feedback, more videos will be created.

Each 3-5 minute video segment will answer one question. Every participant will be asked to answer the following three questions:

1. What is your name, and what do you do in engineering?

2. Can you tell us about your career path?

3. Please describe your/the use of [X technology or engineering concept] in your workplace experiences? Where the technology or concept will depend on their expertise.

Participants will then be asked to speak about topics that were identified by our Program's Department Chairs as important due to their applicability to course material and professional advisors; for example, incorporating sustainability in the workplace, identifying what employers 
look for while hiring, and alternative career options. Other suggestions included using math in the workplace, how is teamwork assessed, how management skills are integrated into a technical work environment, and balancing soft skills with practical skills.

Finally, participants will be asked to identify $1-2$ questions that they would like to answer regarding their personal identity and how it affects them in their workplace. Sample questions include: How has your identity affected your workplace experiences? Please use a specific instance as an example or, simply speak in general terms if you prefer. How has your identity influenced others' perceptions of your family values, time spent with family, or relationship with your family? Or, what aspects of working as a member of a minority group are unique to engineering or may be non-obvious to those entering the field?

These series of questions are meant to introduce the participant, demonstrate their technical knowledge, provide real life examples of these engineers' workplace and their career path, and finally, how their identity influences their past and present workplace experiences. Following the completion of the videos, the Communications and Management instructors will create in-class activities meant to debrief the questions regarding the participants' identity and its implication in the wider Canadian context. Students will be able to discuss the content of the video, which is one of the key benefits of using videos in class, according to Tan and Pearce [23].

\section{THE IMPORTANCE OF DIVERSITY TO THE STUDENTS' WORKPLACE EXPERIENCE}

It is not only important for female students to be able to relate better with their instructors, but it is also important for all students to see females in senior positions, particularly in engineering. In 2016, only $13 \%$ of board positions for companies on the Toronto Stock Exchange (TSX) were female, and $33.3 \%$ of senior management positions were held by women [16].

Per Hango [11], both women and men in hiring positions assumed female applicants would perform worse on a given arithmetic task. Not only is there an issue with the number of female students in engineering and technology, but there is an issue with the number of females being hired with their degree. Employers were twice as likely to choose a male candidate when only shown an image of the person, indicating the stereotype that men are better at science is still a common belief. Women underestimate themselves when self-reported performance levels, while men have no issues boasting their performance, even when men and women are equally skilled. Companies are more likely to hire an unqualified male candidate than a qualified woman [14]. The issue with women underestimating their talents could be a reason why there are less women in STEM programs.

$\mathrm{Du}$ and Kolmos [10] suggest that by changing course content, assessment methods, and skills acquired in engineering programs, gender diversity could increase, as men and women have preferred learning styles. One of the changes included students learning more about professional practice [10], which could be achieved in the B. Tech program, as business professionals could discuss skills seen in successful employees.

By introducing industry and knowledge experts of different ethnicities and genders, either by having a guestlecturer or even by showing people of diversity in videos or other multimedia, more students could be able to view these people as role-models or benefit from different teaching styles.

\section{CONCLUSION}

To increase diversity in the classroom, Northedge [19] proposed the introduction of multiple voices instead of the usual continuous, authoritative single voice. He suggests that students from any background learn best through engagement rather than through being corrected or the ability of reproducing content.

The intended purpose of these videos is not only to diversify the voices in the classroom, as Northedge argued, but to help students retain information longer through deeper level learning, lighten the cognitive load of students, and match a broader spectrum of learning styles. Future research on students' perceptions of these diverse voices and instructors' experiences of using these videos as a teaching tool will contribute to the growing literature on the use of technology and multimedia in engineering classrooms with the unique research question of diversity and representation in the classroom.

\section{Acknowledgements}

The authors wish to acknowledge Allan Mackenzie for the review and feedback on this paper and the Bachelor of Technology program for funding undergraduate student authors to attend the CEEA17 conference.

\section{References}

[1] Ednilson Bernardes \& Mark Hanna, "How do management students prefer to learn? Why should we care?," International Journal for the Scholarship of Teaching and Learning: vol. 3: no. 1, Article 21, 2009 Available at: https://doi.org/10.20429/ijsotl.2009.030121

[2] Brett Bundale, "Glass ceilings still firmly in place," The Chronicle Herald: Business. Retrieved August 22, 2016 from http://thechronicleherald.ca/business/1192078-glass-ceilingsstill-firmly-in-place 
[3] Canadian Association of University Teachers, "The changing academy? A portrait of Canada's university teachers," CAUT Education Review: vol. 12, no. 1. 2010, Available from https://www.caut.ca/docs/education-review/the-changingacademy-a-portrait-of-canada-rsquo-s-university-teachers-(jan2010).pdf?sfvrsn=14

[4] Paul Chandler, and John Sweller, "Cognitive load theory and the format of instruction," Cognition and Instruction. vol 8, no. 4, 40 pp., 1991 Available from

http://www.jstor.org/stable/3233596

[5] Chih-Ming Chen and Chung-Hsin Wu, "Effects of different video lecture types on sustained attention, emotion, cognitive load, and learning performance," Computers \& Education: vol. 80, January 2015, pp. 108-121, 2015

[6] Committee on Developments on the Science of Learning, How People Learn: Brain, Mind, Experience, and School: Expanded Edition. Washington, D.C: The National Academies Press, 2000, 384 pp. \{ISBN: 978-0-309-13197-1\} Available from http://nap.edu/9853

[7] Bari Courts and Jan Tucker, "Using technology to create a dynamic classroom experience," Journal of College Teaching \& Learning - Second Quarter 2012, vol. 9, no. 2, pp. 121-129. Available from https://www.cluteinstitute.com/ojs/index.php/TLC/article/view/6 907

[8] Emily Cruse, "Using education video in the classroom: theory, research and practice," Schlessinger Media, Available from http://www.libraryvideo.com/articles/article26.asp

[9] Thomas Dee, "The race connection: are teachers more effective with students who share their ethnicity?," Education Next: Spring 2004, vol. 4, no. 2, pp. 53-59, 2004. Available from http://educationnext.org/the-race-connection/

[10] Xiangyun Du and Anette Kolmos, "Increasing the diversity of engineering education - a gender analysis in a PBL context" European Journal of Engineering Education, vol. 34, no. 5, October 2009, pp. 425-437

[11] Darcy Hango, "Gender differences in science, technology, engineering, mathematics and computer science (STEM) programs at university" Insights on Canadian Society, December. Statistics Canada Catalogue no. 75-006-X

[12] Florian Hoffmann and Philip Oreoploulos, "A professor like me: the influence of instructor gender on college achievement", Journal of Human Resources, University of Wisconsin Press, vol. 44, no. 2, 2009

[13] Muhamad Fairus Kamaruzaman, M. H. H. Azahari and Rusmadiah Anwar, "Role of video application as an instructional strategy for students learning development," 2012 IEEE Symposium on Humanities, Science and Engineering Research (SHUSER) (Kuala Lumpur, Malaysia, 24-27 June 2012) 4 pp., 2011
[14] Elena Kvochko, "Why there are still few women leaders in tech," Forbes: Tech. Available as of January 6, 2016 from http://www.forbes.com/sites/elenakvochko/2016/01/04/womenexecutives-in-tech/\#6bd6daf74d16

[15] Paul Lam, Dennis Doverspike, and P. Ruby Mawasha, "Increasing diversity in engineering academics (IDEAs): development of a program for improving African American representation" Journal of Career Development, vol. 24, no. 1, Fall 1997.

[16] Andrew MacDougall et al, 2016 Diversity Disclosure Practices: Women in leadership roles at TSX-listed companies Toronto, ON: Osler, Koskin \& Harcourt LLP, 2016, 37 pp.

[17] Allan Mackenzie and Fei Geng, "Enhancing co-op and career development activities through a student-driven mentorship program," Canadian Engineering Education Association Conference (Toronto, ON, 4-7 June 2017)

[18] Richard E. Mayer, "Applying the science of learning to medical education," Medical Education 2010, vol. 44, pp. 543549.

[19] Andrew Northedge, "Rethinking teaching in the context of diversity," Teaching in Higher Education, vol. 8, no. 1, pp. 1732, 2003. Available as of August 25,2010 from http://www.tandfonline.com/doi/abs/10.1080/135625103200005 2302

[20] Royal Bank of Canada, "What is Diversity \& Inclusion?," Available from http://www.rbc.com/diversity/what-isdiversity.html

[21] Andrea Schäfer, "A new approach to increasing diversity in engineering at the example of women in engineering," European Journal of Engineering Education. vol. 31, no. 6, December 2006, pp. 661-671. Available as of October 4, 2011 from http://www.tandfonline.com/doi/abs/10.1080/030437906009117 38 ? journalCode $=$ ceee 20

[22] Stephen D. Sorden, The Cognitive Theory of Multimedia Learning, Mohave Community College/Northern Arizona University, 2012, $31 \mathrm{pp}$. Available from http://sorden.com/portfolio/sorden_draft_multimedia2012.pdf

[23] Elaine Tan \& Nick Pearce, "Open education videos in the classroom: exploring the opportunities and barriers to the use of YouTube in teaching introductory sociology," Research in Learning Technology, vol. 19, iss. 1 sup 1, 2011. Available as of January 27, 2017 from http://www.researchinlearningtechnology.net/index.php/rlt/articl e/view/7783/10461 